\title{
JUSTIÇA AMBIENTAL COMO ESPAÇO PARA CONCRETIZAÇÃO DA CIDADANIA
}

\section{Simone de Oliveira Fraga}

Mestranda da Universidade Federal de Santa Catarina -UFSC. e-mail: sofraga@hotmail.com.

RESUMO: O modelo de desenvolvimento - liberal - assentado nas premissas: individualismo econômico e mercado, apresenta os primeiros sinais da sua problemática sócio-ambiental no final dos anos 60. A crescente crise civilizatória é provocada não só porque os recursos naturais, à medida que vão sendo degradados, não são renováveis, e os que possuem tal qualidade, demoram gerações para serem recuperados, como também, em razão do modelo de desenvolvimento adotado, operou-se um desequilíbrio ambiental que ameaça a sobrevivência da espécie humana, bem como, na esteira de seus efeitos, temos o aumento do desemprego pela quase total mecanização dos meios de produção, a miséria, e a marginalidade social. Em contextos em que as desigualdades são ainda maiores como é o caso do Brasil, a universalização da temática do movimento da justiça ambiental alcança outras finalidades além das relacionadas ao meio ambiente, pois, denuncia o violento quadro de injustiça social causado pela desigual distribuição do poder e da riqueza e pela apropriação pelas classes ricas do território e dos recursos naturais. Mas a busca pela equidade ambiental não encontra respaldo na lógica do capitalismo que é quem mais se beneficia com a desigual divisão do risco, por sua vez, a esfera econômica influencia a esfera estatal, que sem a mobilização da sociedade civil permanece omissa e inoperante. Somente através da atuação dos cidadãos o Estado será compelido a reverter a lógica capitalista de forma que este sistema promova a realização de uma economia voltada, não para o crescimento, mas para a sustentabilidade, e desta forma produza resultados positivos no âmbito da justiça ambiental.

PALAVRAS-CHAVE: Crise Civilizatória. Desigualdades. Justiça Ambiental. Racionalidade Econômica. Acumulação de Capital. Ecologismo Ingênuo. Direitos Sócioambientais. Cidadania. Discriminação. Injustiça Social. Lógica do Mercado. Modernização. Risco. Divisão Social do Ambiente. Modernização Ecológica. Ecologismo. Participação da Sociedade Civil. Sustentabilidade. 


\section{INTRODUÇÃO: PROBLEMÁTICA SÓCIOAMBIENTAL OU CRISE CIVILIZATÓRIA.}

O modelo de desenvolvimento - liberal - assentado nas premissas: individualismo econômico e mercado, como resultado da "articulação entre propriedade privada, iniciativa econômica privada e mercado"1, apresenta os primeiros sinais da sua problemática sócio-ambiental no final dos anos $60 .^{2}$

Esse modelo de crescimento orientado para objetivos materiais $\mathrm{e}$ econômicos puramente individualista, regido por regras jurídicas de natureza privada, dissociou a natureza da economia, alheando desta, os efeitos devastadores dos princípios econômicos na natureza, "os serviços ambientais, (...) mais não são, (...) do que bens livres, exteriores por definição aos mecanismos de condução da actividade econômica". ${ }^{3}$

Do final da década de 60 até a década de 80, a maior preocupação com a natureza se dava em relação ao receio do esgotamento dos recursos naturais que possuíssem interesses econômicos envolvidos, assim a preocupação estava circunscrita, quase que exclusivamente, ao petróleo ${ }^{4}$. Até este momento, no centro da questão de meio ambiente se encontrava a preocupação com a sobrevivência da espécie humana, numa visão de viés puramente econômico.

A crescente crise civilizatória é provocada não só porque os recursos naturais, à medida que vão sendo degradados, não são renováveis e os que possuem tal qualidade, demoram gerações para serem recuperados, como também, em razão do modelo de desenvolvimento adotado operou-se um desequilíbrio ambiental que ameaça a sobrevivência da espécie humana, bem como, na esteira de seus efeitos, temos o aumento do desemprego pela quase total mecanização dos meios de produção, a miséria, e a marginalidade social.

\footnotetext{
1 PUREZA, José Manuel; FRADE, Catarina. Direito do Ambiente. I Parte: A Ordem Ambiental Portuguesa. Universidade de Coimbra,2001

2 ALEXANDRE, Agripa Faria. A perda de Radicalidade do Movimento Ambientalista Brasileiro. Uma contribuição à critica do movimento. Blumenau-Florianópolis:Edifurb.Editora da UFSC.2000.p.23. Cf também PUREZA, José Manuel; FRADE, Catarina. Direito do Ambiente. I Parte: A Ordem Ambiental Portuguesa. Universidade de Coimbra,2001

3 PUREZA, José Manuel; FRADE, Catarina. Direito do Ambiente. I Parte: A Ordem Ambiental Portuguesa. Universidade de Coimbra,2001

44 BROWN, Lester R..Por uma Sociedade Viável. Rio de Janeiro: editora da fundação Getulio Vargas.1983,p.63.
} 
As Nações Unidas ${ }^{5}$, com a Declaração de Estocolmo sobre o Meio Ambiente e Desenvolvimento em 1972, e posteriormente, a Convenção das Nações Unidas de 1992 e a ECO-92, inauguraram um novo paradigma e, então, passou-se a encarar o meio ambiente como bem autônomo, imaterial e interdependente. Essa mudança paradigmática trouxe a novidade de retirar o homem do centro da discussão e o incluiu no conceito de meio ambiente como os demais seres vivos, interagindo de forma integrada e interativa.

Buscou-se, também, apresentar uma alternativa viável para o desenvolvimento econômico que englobasse a natureza, de forma a apresentar uma solução intermediária entre um desenvolvimento baseado numa "racionalidade econômica de curto prazo, orientada para acumulação de capital" ${ }^{\text {e }}$ e um ecologismo ingênuo ${ }^{7}$.

Segundo Lester R. Brown ${ }^{8}$, as ameaças à civilização são causadas pela erosão do solo, a deterioração dos sistemas biológicos e o esgotamento das reservas petrolíferas. Tais ameaças geram tensões ambientais que se materializam em crise econômica, causada pela dependência de alguns países dos produtos alimentícios vindos de outros países, bem como das fontes de energia produzidas pelos combustíveis fósseis.

A proposta deste estudo é analisar a situação da justiça ambiental no Brasil, a partir dos direitos socioambientais constitucionalmente assegurados, mas ainda em construção. Pois, antes de tudo, constata-se que a forma da sociedade combater as injustiças ambientais está umbilicalmente ligada ao exercício da cidadania. ${ }^{9}$

${ }^{5}$ Estas são na realidade declarações e não propriamente cartas de direitos e se localizam no âmbito do Direito Internacional, conforme BOBBIO enquanto não ratificadas não passam de diretivas gerais pautadas pela crença nas boas intenções ou boa vontade dos Estados membros. BOBBIO, Norberto. A Era dos Direitos. Campus. Rio de Janeiro. 1992.

6 PUREZA, José Manuel; FRADE, Catarina. Direito do Ambiente. I Parte: A Ordem Ambiental Portuguesa. Universidade de Coimbra,2001

7 ALEXANDRE, Agripa Faria. A perda de Radicalidade do Movimento Ambientalista Brasileiro. Uma contribuição à critica do movimento. Blumenau-Florianópolis:Edifurb.Editora da UFSC.2000.p.23.

8 BROWN, Lester R..Por uma Sociedade Viável. Rio de Janeiro: editora da fundação Getulio Vargas.1983,p.5.

${ }^{9}$ ACSELRAD, Henri. Justiça ambiental - ação coletiva e estratégias argumentativas. IN ACSELRAD, Henri; HERCULANO, Selene; PÁDUA. José Augusto (orgs). Justiça Ambiental e Cidadania. Rio de Janeiro: Relume Dumará, 2004.p.24. 


\section{A DINÂMICA DAS LUTAS SOCIOAMBIENTAIS.}

A partir da década de 60, do século passado, os efeitos devastadores do desenvolvimento técnico e científico começaram a repercutir, não só no campo das ciências sociais, humanas, e biológicas, como também chegaram ao tecido social.

Como corolário da crise socioambiental surgiu, nos Estados Unidos, a noção de justiça ambiental ${ }^{10}$, nascida da criatividade, principalmente, dos movimentos sociais forjados pela luta dos afrodescendentes, que protestavam pela discriminação causada pela maior exposição desta população aos lixos químicos, radioativos, e indústrias com efluentes poluentes.

Em contextos em que as desigualdades são ainda maiores, como é o caso do Brasil, a universalização da temática do movimento ${ }^{11}$ da justiça ambiental alcança outras finalidades além das relacionadas ao meio ambiente, pois denuncia o violento quadro de injustiça social causado pela desigual distribuição do poder e da riqueza e pela "apropriação elitista do território e dos recursos naturais". ${ }^{12}$

A sociedade moderna, moldada nos ideais das revoluções burguesas, trouxe no seu bojo a idéia de liberdade na constituição das relações sociais, a partir da vontade de cada indivíduo, rompendo desta forma com os estamentos, que eram o modelo de sociedade da idade média e cujas relações sociais são como pré-fixadas e regidas pela tradição que tornava praticamente impossível a mobilidade social. Destarte, há uma modificação da realidade a partir da era moderna, a qual terá no

${ }^{10}$ Por justiça ambiental, portanto passou-se a entender, desde as primeiras lutas que evocaram tal noção no início dos anos 80, o conjunto de princípios que asseguram que nenhum grupo de pessoas, sejam grupos étnicos, raciais ou de classe, suporte uma parcela desproporcional de degradação do espaço coletivo. Complementarmente, entende-se por injustiça ambiental a condição de existência coletiva própria a sociedades desiguais onde operam mecanismos sóciopolíticos que destinam a maior carga dos danos ambientais. ACSELRAD, Henri; HERCULANO, Selene; PÁDUA. José Augusto (orgs). Justiça Ambiental e Cidadania. Rio de Janeiro: Relume Dumará, 2004.p.9.

${ }^{11}$ Consideramos que o termo justiça ambiental é um conceito aglutinador e mobilizador, por integrar as dimensões ambiental, social e ética da sustentabilidade e do desenvolvimento, freqüentemente dissociados nos discursos e nas práticas. Tal conceito contribui para reverter a fragmentação e o isolamento de vários movimentos sociais frente ao processo de globalização e reestruturação produtiva que provoca perda de soberania, desemprego, precarização do trabalho e fragilização do movimento sindical e social como todo. Justiça ambiental, mais que uma expressão do campo do direito, assume-se como campo de reflexão, mobilização e bandeira de luta de diversos sujeitos e entidades, como sindicatos, associações de moradores, grupos de afetados por diversos riscos (como as barragens e várias substâncias químicas), ambientalistas e cientistas. ACSELRAD, Henri; HERCULANO, Selene; PÁDUA. José Augusto (orgs). Justiça Ambiental e Cidadania. Rio de Janeiro: Relume Dumará, 2004.p.18.

12 ACSELRAD, Henri; HERCULANO, Selene; PÁDUA. José Augusto (orgs). Justiça Ambiental e Cidadania. Rio de Janeiro: Relume Dumará, 2004.p.10. 
direito os trilhos por onde o indivíduo deverá caminhar a fim de garantir que sua vontade livre atinja os objetivos necessários para sua sobrevivência. ${ }^{13}$

Nesta nova sociedade, em que o direito se estabelece como garantia da realização do egoísmo individual, três figuras jurídicas se destacam: a posse, a propriedade e o contrato. Combinado com a liberdade de trabalho, o papel do Estado será o de garantir a liberdade, reduzindo o seu espectro político a mero Estado de direito.

Com isso, cria-se uma contradição, pois o ideal da liberdade e a igualdade de oportunidades, nascidas dos ideais burgueses são traídas pela lógica das necessidades materiais do individuo. ${ }^{14}$

No âmbito da justiça ambiental, a lógica do mercado tem imprimido aos seus atos uma capacidade de resolver seus problemas institucionais sem romper com o padrão de modernização exigida pelo capital, alcançando o consenso político eles tornam o Poder Público seu parceiro, ou cúmplice. ${ }^{15}$

A realidade da natureza entra em conflito com o mundo regido pelas relações jurídicas e com o mundo regido pelas ralações econômicas, onde, na maior parte das vezes, a realidade econômica saí vitoriosa no embate de forças. “ Enquanto os tribunais - mediante seus raciocínios formais - dão expressão à 'fictiva' verdade jurídica, em relação à realidade ecológica, a natureza revela, por sua maneira física e inequívoca, a verdade ecológica. ${ }^{16}$

As ações patrocinadas, principalmente, pelos movimentos sociais são fatores decisivos para mudar a realidade acima descrita, muito embora, no Brasil, a idéia de cidadania muitas vezes se confunda apenas com o exercício do voto, e

13 VIEIRA, Luiz Vicente. Os MovimentosSociais e o Espaço Autônomo do "Político". Porto Alegra: Edipucrs, 2004. p.308.

14 VIEIRA, Luiz Vicente. Os MovimentosSociais e o Espaço Autônomo do "Político". Porto Alegra: Edipucrs, 2004. p.308.

15 Empresas de serviço de limpeza industrial, com autorização estatal, procedem à eliminação de dejetos tóxicos no mar, com plena consciência das conseqüências ecológicas:da degradação dos mares.(...); extinção de espécies marinhas eaté mudanças climatológicas. WOLF, Paul. A irresponsbilidade organizada? Comentários sobre a função simbólica do direito Ambiental. In OLIVEIRA Jr. José Alcebiades. O Novo em Direito e Política. Porto Alegre: Livraria do Advogado,1997.p.182.

${ }^{16}$ O interesse ecológico é protregido apenas de maneira simbólica, consoante o Direito Ecológico estatal coloca em cena uma pseudo-realidade. Sua manifestação simbólica (na forma de obras legislativas, declarações de direitos ecológicos constitucionais, instituições, atos administrativos e decisões judiciais) cria a falsa impressão de que existe ativa e completa assistência, bem como prevenção ecológica, por parte do Estado. WOLF, Paul. A irresponsbilidade organizada? Comentários sobre a função simbólica do direito Ambiental. In OLIVEIRA Jr. José Alcebiades. O Novo em Direito e Política. Porto Alegre: Livraria do Advogado,1997.p. 183,188 
onde a maior parte da população não tem sequer consciência dos seus direitos, a temática da justiça ambiental vai mais além da contaminação provocada pela poluição nas comunidades mais carentes, abrange, entre outras lutas, a expulsão das comunidades tradicionais dos locais onde vivem e trabalham para a construção de barragens, exploração do potencial hidrelétrico, exploração mineral, exploração madereira e, atualmente, a transposição do rio São Francisco. ${ }^{17}$

Não podemos falar em crise civilizatória e justiça ambiental sem pensarmos que os conflitos nascidos do desenvolvimento iniciado no século XIX, que deram origem à sociedade pós-industrial, nasceram da modernização que dissolveu a sociedade agrária paralisada no estamento e elaborou a imagem da sociedade industrial. A sociedade pós-industrial, por sua vez, dissolve os contornos da sociedade industrial, e na continuidade da modernidade surge outra figura social, a sociedade do risco ${ }^{18}$.

\section{A INJUSTIÇA AMBIENTAL E A SOCIEDADE DE RISCO.}

O século $X X$ não foi pobre em catástrofes globais. Em suas duas guerras mundiais, onde se desenvolveu tecnologia suficiente para a extinção massificada de seres humanos: Auschwitz e Nagasaki. Outras catástrofes ligadas à atuação humana podem ser citadas: Harrisburg (acidente nuclear ocorrido em Three Mille Island, Pensilvânia, em 28/03/1979), Bhopal (vazamento de gás tóxico de uma fábrica de pesticidas, que matou 3.300 pessoas, em 4/01/1984) e Chernobyl ${ }^{19}$. Este último acidente trouxe, para a humanidade, incertezas a respeito de seu próprio futuro, pois, neste atual estágio de desenvolvimento foi introduzido uma nova noção ao seu cotidiano já complexo, a noção do risco, sobre o qual não se tem controle e do qual não se pode escapar.

Num mesmo momento histórico, duas lógicas se digladiam: a lógica da produção de riqueza e a lógica da repartição dos riscos. Enquanto para as sociedades ricas economicamente, os problemas da justiça ambiental se restringem

17 ACSELRAD, Henri; HERCULANO, Selene; PÁDUA. José Augusto (orgs). Justiça Ambiental e Cidadania. Rio de Janeiro: Relume Dumará, 2004.p.10.

18 BECK, Ulrick. La sociedad del riesgo. Hacia una nueva modernidad. Barcelona: Ediciones Paidós Ibérica,1998.p.16.

19 BECK, Ulrick. La sociedad del riesgo. Hacia una nueva modernidad. Barcelona: Ediciones Paidós Ibérica,1998.p.8. 
à preocupação com a repartição desproporcional dos riscos trazidos pelo desenvolvimento entre todos os que convivem naquela sociedade. Nos países pobres, como o Brasil $^{20}$, onde existe uma enorme injustiça no que diz respeito à distribuição de renda, o escopo do movimento da justiça ambiental ultrapassa as fronteiras da problemática relacionada à localização dos depósitos de dejetos poluentes ou fontes de contaminação, "é preciso considerar, por exemplo, tanto as carências de saneamento ambiental no meio urbano quanto, no meio rural, a degradação das terras usadas para acolher os assentamentos de reforma agrária. Não são apenas os trabalhadores industriais e os moradores no entorno das fábricas aqueles que pagam, com sua saúde e suas vidas, os custos das chamadas 'externalidades' da produção de riquezas, mas também os moradores dos subúrbios e periferias urbanas"21.

Temos, ainda, a considerar que duas realidades devem ser distinguidas. A realidade interna dos países ricos, onde os efeitos do desenvolvimento produzem insegurança e risco ambiental no seio daquela sociedade. E a realidade externa, ou seja, a realidade internacional, em que o desenvolvimento produz riscos para os demais países, em face da sua natureza transfronteiriça. ${ }^{22}$

O primeiro aspecto, relativo ao risco produzido internamente nos países ricos, e onde as lutas dos movimentos pela justiça ambiental se encontram consolidados, não é objeto do nosso estudo, bem como, no âmbito internacional, os

${ }^{20}$ As gigantescas injustiças sociais brasileiras encobrem e naturalizam um conjunto de situações caracterizadas pela desigual distribuição de poder sobre a base material da vida social e do desenvolvimento. A injustiça e a discriminação, portanto, aparecem na apropriação elitista do território e dos recursos naturais, na concentração dos benefícios usufruídos do meio ambiente e na exposição desigual da população à poluição e aos custos ambientais do desenvolvimento. ACSELRAD, Henri; HERCULANO, Selene; PÁDUA. José Augusto (orgs). Justiça Ambiental e Cidadania. Rio de Janeiro: Relume Dumará, 2004.p.10.

${ }^{21}$ A expansão do modelo de desenvolvimento dominante na agroindústria brasileira, por exemplo, temse associado à inviabilização da pequena agricultura familiar, da reprodução dos grupos indígenas, da pesca artesanal e do abastecimento de água para as comunidades. ACSELRAD, Henri; HERCULANO, Selene; PÁDUA. José Augusto (orgs). Justiça Ambiental e Cidadania. Rio de Janeiro: Relume Dumará, 2004.p.12.

${ }^{22}$ Ao mesmo tempo, os riscos produzem novas desigualdades internacionais, por uma parte entre os países pobres e os Estados industrializados, por outra parte entre os mesmos Estados industrializados. Essas desigualdades não respeitam o tecido de competência do Estado nacional. A vista da universalidade e supranacionalidade do tráfico de substancias nocivas, a sobrevivência dos bosques da Baviera depende em última instancia que sejam firmados e cumpridos os tratados internacionais.[ tradução livre nossa] BECK, Ulrick. La sociedad del riesgo. Hacia una nueva modernidad. Barcelona: Ediciones Paidós Ibérica,1998.p.29. Al miesmo tiempo, los riesgos producen nuevas desigualdades internacionales, por una parte entre el Tercer Mundo y los Estados industrializados, por otra parte entre los mismos Estados industrializados. Esas desigualdades no respetan el tejido de competencias del Estado nacional. A la vista de la universalidad u supranacionalidad del tráfico de sustancias nocivas, la supervivencia de los bosques de Baviera depende en última instancia de la firma y cumplimiento de tratados internacionales. 
riscos sofridos pelos próprios países ricos, em face dos problemas relativos a degradação ambiental que não respeitam fronteiras.

Cumpre-nos analisar os riscos importados pelos países pobres, que muitas das vezes são obrigados a suportarem o lixo resultante da prosperidade dos países ricos.

Não bastando as agressões ao meio ambiente, resultante da produção industrial dos países ricos suportada pelos países pobres, temos, também, a degradação ambiental provocada pela especulação do capital, onde é gerada uma "espécie de divisão social do ambiente"23. A população é desconsiderada pela a política econômica, baseada na atração do capital internacional que utilizando sua capacidade de escolher os locais preferenciais para seus investimentos, força as populações a se conformarem com os riscos produzidos pela indústria instalada na proximidade de suas residências, uma vez que, não possuem condições de se retirarem do local, ou são levadas a um deslocamento forçado, quando se encontram instaladas em ambientes favoráveis aos investimentos.

O comportamento das empresas é respaldado pela ação do governo no sentido de apresentar ações para uma denominada "modernização ecológica" ${ }^{24}$, agindo sob a lógica do mercado, buscando promover ganhos de eficiência e ativar mercados, procurando essencialmente evitar, o que para estes atores é o núcleo da questão ambiental, o desperdício de matéria e energia. "A questão ambiental poderia ser apropriadamente internalizada pelas próprias instâncias do capital, de modo a absorver e neutralizar as virtualidades transformadoras do ecologismo." ${ }^{25}$

$\mathrm{Na}$ esfera pública, os governos apresentam planos para a modernização ecológica. Atualmente, temos o PPA - Plano Plurianual 2000-2003, denominado "Avança Brasil", em substituição ao Programa "Brasil em Ação" - 1994/1998 - do governo anterior.

\footnotetext{
23 ACSELRAD, Henri. Justiça ambiental - ação coletiva e estratégias argumentativas. IN ACSELRAD, Henri; HERCULANO, Selene; PÁDUA. José Augusto (orgs). Justiça Ambiental e Cidadania. Rio de Janeiro: Relume Dumará, 2004.p.32.

${ }^{24}$ A noção de 'modernização ecológica', (...), designa o processo pelo qual as instituições políticas internalizam preocupações ecológicas no propósito de conciliar o crescimento econômico com a resolução dos problemas ambientais, dando-se ênfase à adaptação tecnológica, à celebração da economia de mercado BLOWERS,A. citado por ACSELRAD, Henri. Justiça ambiental - ação coletiva e estratégias argumentativas. IN ACSELRAD, Henri; HERCULANO, Selene; PÁDUA. José Augusto (orgs). Justiça Ambiental e Cidadania. Rio de Janeiro: Relume Dumará, 2004.p.23.
} 
O "Avança Brasil" tem como finalidade integrar e desenvolver o país e pretende investir R $\$ 24,1$ bilhões, dos setores públicos e privados, na construção de rodovias, hidrovias, ferrovias, portos e geração de energia.

Algumas áreas estão mais sujeitas ao risco do desenvolvimento, ante a inexistência de regulação a respeito do parcelamento do solo, e a realização de um zoneamento excludente, de forma a promover práticas discriminatórias que beneficiam uma elite poderosa política e economicamente.

Tomando como exemplo a Amazônia, que está contemplada no PPA, segundo o IPAM - Instituto de Pesquisa ambiental da Amazônia, após a abertura das rodovias na região, nos últimos 30 anos foram desmatados $50 \mathrm{~km}$ de floresta em cada margem, e que são estimados o desmatamento, nos próximos 25 a 35 anos,

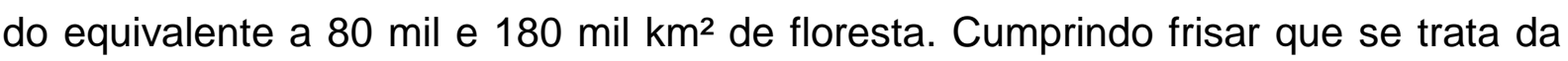
região que possui cerca de $50 \%$ da biodiversidade global. ${ }^{26}$

Neste contexto, a população, que em 1996 era de 18,1 milhões de habitantes, segundo o IBGE, que aponta, conforme dados mais atualizados para uma população de 25 milhões de habitantes, sendo que destes, 20 milhões vivem em centros urbanos. População composta de um conjunto significativo de comunidades sócio-culturalmente diferenciadas, boa parte históricamente vinculada à Amazônia, não são objeto de consulta ou de preocupação. Não obstante se encontrarem protegidos pela Constituição Federal, nos artigos 231, 215 e 216, e reconhecidas nacionalmente e internacionalmente como importantes para a conservação, principalmente, da diversidade biológica, não existem estudos suficientes a respeito destas populações ${ }^{27}$.

No trabalho que caminha em sentido oposto, temos os aspectos apresentados por aqueles que desenvolvem um modelo de justiça ambiental, que denunciam as falhas da "modernização ecológica", mormente porque esta ignora a relação entre a degradação ambiental e o modelo de desenvolvimento liberal,

${ }^{25}$ ACSELRAD, Henri. Justiça ambiental - ação coletiva e estratégias argumentativas. IN ACSELRAD, Henri; HERCULANO, Selene; PÁDUA. José Augusto (orgs). Justiça Ambiental e Cidadania. Rio de Janeiro: Relume Dumará, 2004.p.23.

26 LIMA, André. Direitos Socioambientais, Políticas Públicas e Desenvolvimento Territorial,In LIMA, André (org). O Direito para o Brasil SocioAmbiental. Porto Alegre: Sergio Antonio Fabris Editor. 2002, pp. 324/329.

${ }^{27}$ LIMA, André. Direitos Socioambientais, Políticas Públicas e Desenvolvimento Territorial,In LIMA, André (org). O Direito para o Brasil SocioAmbiental. Porto Alegre: Sergio Antonio Fabris Editor. 2002, pp. 324/329. 
"assente em dois pressupostos fundamentais: primeiro, 0 individualismo metodológico e dogmático, traduzido na adoção do homo economicus e na maximização da satisfação individual como padrão de racionalidade social e econômica; depois, a crença no sistema de auto-regulação como mecanismo preservador da "ordem natural" invisivelmente resultante da articulação entre propriedade privada, iniciativa econômica privada e mercado" ${ }^{28}$.

Este trabalho de oposição à chamada modernização ecológica, levada a cabo pelo movimento de justiça ambiental, decorreu principalmente da sua capacidade de estender os direitos civis ao campo do meio ambiente, politizar, nacionalizar e unificar uma multiplicidade de embates, elaborar uma classificação apropriada dos grupos sociais compatível com sua posição no espaço social, organizar informações e vigiar os riscos ambientais, preenchendo o espaço vazio deixado pelos partidos políticos.

Resultando na redução da capacidade de escolha locacional do capital, com isso mostrar sua força ao dificultar a rentabilidade esperada do capital, e principalmente, barrando uma poderosa arma utilizada como chantagem por este mesmo capital, a sua capacidade de mobilidade espacial. ${ }^{29}$

\section{CONCLUSÃO: A PRÁTICA DA CIDADANIA COMO SOLUÇÃO.}

A Constituição Federal representou um importante avanço no que diz respeito aos direitos sócio-ambientais, e inúmeras leis infra-constitucionais regulamentam estes direitos, mas não obstante as garantias constitucional e legal, a realidade da vida demonstra que a realização destes direitos se encontram, ainda, muito distantes de serem concretizados, uma vez que, precisam de demandas públicas e participação direta da população.

28 PUREZA, José Manuel; FRADE, Catarina. Direito do Ambiente. I Parte: A Ordem Ambiental Portuguesa. Universidade de Coimbra,2001.

29 BULARD, Robert. Enfrentando o racismo ambiental no século XXI. IN ACSELRAD, Henri; HERCULANO, Selene; PÁDUA. José Augusto (orgs). Justiça Ambiental e Cidadania. Rio de Janeiro: Relume Dumará, 2004.p.34. 
A justiça ambiental tem como principal ferramenta a participação da sociedade civil $^{30}$, promovendo ações para prática da cidadania ${ }^{31}$, numa articulação discursiva diferente do debate pelo meio ambiente equilibrado, pois remete à idéia de distribuição igual e diferenciação qualitativa do meio ambiente, contrapondo-se a prática da "distribuição desigual das partes de um meio ambiente de diferentes qualidades e injustamente dividido"32.

Certas pré-condições se estabelecem para que as práticas coletivas dos movimentos sociais ocorram, tais como: a perda de legitimidade de alguns aspectos do sistema de poder; grupos sociais, antes conformados, passam a afirmar princípios de justiça que impõem demandas; individualmente, as pessoas passam a acreditar que podem mudar alguma coisa. Por fim, os movimentos sociais passam a intervir nos dois níveis do espaço social - no espaço da distribuição do poder e no espaço da luta discursiva, neste caso, o MST é um exemplo de movimento que atua nos dois espaços ${ }^{33}$.

As comunidades que mais expostas se encontram dos riscos da contaminação, são as que no espaço da distribuição do poder na sociedade capitalista, menos poder político detém, tal realidade somente seria invertida com a intervenção política para estabelecer parâmetros razoáveis de justiça ambiental, mas a busca pela eqüidade ambiental não encontra respaldo na lógica do capitalismo, que é quem mais se beneficia com a desigual divisão do risco, por sua vez, a esfera econômica influencia a esfera estatal, que sem a mobilização da sociedade civil permanece omissa e inoperante.

${ }^{30}$ Sociedade civil representa uma esfera de discurso público dinâmico e participativo entre o Estado, a esfera pública composta de organizações voluntárias, e a esfera do mercado referente a empresas privadas e sindicatos. JANOSKI, citado por VIEIRA, Liszt. Os argonautas da cidadania:A sociedade civil na globalização. Rio de Janeiro.São Paulo: Editora Record,2001,p.36.

${ }^{31}$ Constata-se que cidadania e sociedade civil são noções diferentes: ao passo que a primeira é reforçada pelo Estado, a última abrange os grupos em harmonia ou conflito, mas ambas são empiricamente contigentes.(...) Além disso, a sociedade civil consiste primordialmente na esfera pública, onde associações organizações se engajam em debates, de forma que a maior parte das lutas pela cidadania são realizadas em seu âmbito por meio dos interesses dos grupos sociais, embora - cabe a ressalva - a sociedade civil não possa constituir locus dos direitos de cidadania, por não se tratar da esfera estatal, que assegura proteção oficial mediante sanções legais. VIEIRA, Liszt. Os argonautas da cidadania:A sociedade civil na globalização. Rio de Janeiro.São Paulo: Editora Record,2001,p.36.

32 ACSELRAD, Henri. Justiça ambiental - ação coletiva e estratégias argumentativas. IN ACSELRAD, Henri; HERCULANO, Selene; PÁDUA. José Augusto (orgs). Justiça Ambiental e Cidadania. Rio de Janeiro: Relume Dumará, 2004.p.28.

${ }^{33}$ ACSELRAD, Henri. Justiça ambiental - ação coletiva e estratégias argumentativas. IN ACSELRAD, Henri; HERCULANO, Selene; PÁDUA. José Augusto (orgs). Justiça Ambiental e Cidadania. Rio de Janeiro: Relume Dumará, 2004.p.28. 
As práticas coletivas na sociedade civil necessitam, antes de mais nada, da prática permanente da cidadania, entendida esta como a "relação entre Estado e cidadão, especialmente no tocante a direitos e obrigações" ${ }^{34}$. Somente através da atuação dos cidadãos, o Estado será compelido a reverter a lógica capitalista de forma que este sistema promova a realização de uma economia voltada não para o crescimento, mas para a sustentabilidade, e desta forma, produza resultados positivos no âmbito da justiça ambiental.

\section{BIBLIOGRAFIA}

ALEXANDRE, Agripa Faria. A perda de Radicalidade do Movimento Ambientalista Brasileiro. Uma contribuição à critica do movimento. Blumenau-Florianópolis:Edifurb.Editora da UFSC.2000.p.23. Cf também PUREZA, José Manuel; FRADE, Catarina. Direito do Ambiente. I Parte: A Ordem Ambiental Portuguesa. Universidade de Coimbra,2001.

ACSELRAD, Henri; HERCULANO, Selene; PÁDUA. José Augusto (orgs). Justiça Ambiental e Cidadania. Rio de Janeiro: Relume Dumará, 2004.

. Justiça ambiental - ação coletiva e estratégias argumentativas. IN ACSELRAD, Henri; HERCULANO, Selene; PÁDUA. José Augusto (orgs). Justiça Ambiental e Cidadania. Rio de Janeiro: Relume Dumará, 2004.

BECK, Ulrick. La sociedad del riesgo. Hacia una nueva modernidad. Barcelona: Ediciones Paidós Ibérica,1998.

BROWN, Lester R..Por uma Sociedade Viável. Rio de Janeiro: editora da fundação Getulio Vargas.1983.

BULARD, Robert. Enfrentando o racismo ambiental no século XXI. IN ACSELRAD, Henri; HERCULANO, Selene; PÁDUA. José Augusto (orgs). Justiça Ambiental e Cidadania. Rio de Janeiro: Relume Dumará, 2004.

JANOSKI, citado por VIEIRA, Liszt. Os argonautas da cidadania:A sociedade civil na globalização. Rio de Janeiro.São Paulo: Editora Record,2001.

LIMA, André. Direitos Socioambientais, Políticas Públicas e Desenvolvimento Territorial,In LIMA, André (org). O Direito para o Brasil SocioAmbiental. Porto Alegre: Sergio Antonio Fabris Editor. 2002.

34 VIEIRA, Liszt. Os argonautas da cidadania:A sociedade civil na globalização. Rio de Janeiro.São Paulo: Editora Record,2001,p.33. 
PUREZA, José Manuel; FRADE, Catarina. Direito do Ambiente. I Parte: A Ordem Ambiental Portuguesa. Universidade de Coimbra,2001.

VIEIRA, Luiz Vicente. Os MovimentosSociais e o Espaço Autônomo do "Político". Porto Alegra: Edipucrs, 2004.

WOLF, Paul. A irresponsbilidade organizada? Comentários sobre a função simbólica do direito Ambiental. In OLIVEIRA Jr. José Alcebiades. O Novo em Direito e Política. Porto Alegre: Livraria do Advogado,1997. 